\title{
Atmospheric Corrosion Of ASTM A-242 And ASTM A-588 Weathering Steels In Different Types Of Atmosphere
}

Díaz, I; Cano Cuadro, Heidis Patricia; Crespo, David; Chico, Belén; De La Fuente García, Daniel; Morcillo, Manuel

\begin{abstract}
The work analyses the atmospheric corrosion resistance of two widely used weathering steels: ASTM A-242 and ASTM A-588. The steels were exposed for up to 5 years in different types of atmosphere: rural, urban, industrial and marine. The atmospheric corrosion resistance of the steels was evaluated and the rust layers formed on them were characterised by X-ray diffraction, optical microscopy and scanning electron microscopy. The most relevant conclusions reached include the following: (a) the visual appearance (colouring) of the rust, rust texture, nature of the corrosion products and compactness of the rust layers formed are similar in both types of weathering steel. (b) No great differences are observed in the corrosion resistance. Slight differences occur in the industrial atmosphere, where ASTM A-242 presents 10-13\% less corrosion than ASTM A-588. (c) In the C2-C3 ISO corrosivity atmosphere both types of weathering steels are adequate for unpainted use. However are not suitable in higher ISO corrosivity atmosphere.
\end{abstract}

\section{Keywords}

ASTM A-242; ASTM A-588; Atmospheric Corrosion; Industrial; Marine; Rural; Urban; Weathering Stee. 